\title{
Mechanical response of surrounding rock of tunnels constructed with the TBM and drill-blasting method
}

\author{
Feng Ji $\cdot$ Junfu Lu $\cdot$ Yuchuan Shi $\cdot$ Chunhong Zhou
}

Received: 25 August 2012/ Accepted: 14 November 2012/Published online: 25 November 2012

(C) The Author(s) 2012. This article is published with open access at Springerlink.com

\begin{abstract}
There are two kinds of excavation methods in underground engineering: the tunnel boring machine (TBM) and the drill-blasting method. A large number of studies have shown that the deformation and failure, the degree of disturbance, the stability and the reinforcement measures of surrounding rock using the TBM and drill-blasting method vary from each other. To accurately master these macroscopic damages, it is necessary to focus on the investigation of the micro-mechanical responses of the surrounding rock. Scanning electron microscopy tests, acoustic emission tests and tunnel acoustic detection tests were carried out to analyze the mechanical response of surrounding rock of tunnels, which were excavated in marble by, respectively, the TBM and the drill-blasting method. The tests results showed that most of the rock fractures cut by TBM is wipe along the crystal, and the failure mechanism is mainly cutting, while most of the rock fractures induced by the TBM coincide with crystal planes, its mechanism is mainly tensile. The stress-strain curves of rocks cut by the TBM method are rather flat around the peak strength, which means a strong resistance to deformation around the peak load. The response of $\mathrm{AE}$ for the rock cut by the TBM method appears after larger strains than the response of the rock constructed by the drill-blasting method. This suggests that the resistance to damage is higher under TBM excavation conditions. The relaxation depths of the tunnel excavated by the drillblasting method are larger than the tunnel excavated by the TBM method. The research can provide more insight into tunnel failure mechanisms and provide a framework for reinforcement measures.
\end{abstract}

F. Ji (ه) · J. Lu (ه) · Y. Shi (ه)

State Key Laboratory of Geohazard Prevention and Geoenvironment Protection,

Chengdu University of Technology, Chengdu 610059, China

e-mail: jeifens@163.com

J. $\mathrm{Lu}$

e-mail: 108358611@qq.com

Y. Shi

e-mail: syczxq@sina.com

C. Zhou

East China Investigation and Design Institute, China Hydropower Engineering Consulting Group

Corporation, Hangzhou 310014, China 
Keywords TBM - Drill-blasting method $\cdot$ Scanning electron microscope $\cdot$ Acoustic emission $\cdot$ Mechanical response

\section{Introduction}

At present, the tunneling methods are mainly TBM (tunnel boring machine) and drillblasting. A large number of studies have shown that the deformation and failure, the selfstability and the reinforcement measures caused by varying construction methods are different. Recently, a lot of research was carried out about the macroscopic characteristics related to among others the stress distribution state, the relaxation depth and the integrity of the surrounding rock.

Ribacchi analzsed the influence of rock mass quality on the performance of TBM for the excavation of a tunnel in a gneiss formation (Ribacchi and Fazio 2005). Li gave a brief explanation of the failure mechanism of rock fragmentation in rock cutting using the nonlinear dynamic finite element software LS/DYNA to simulate the dynamic process of rock cutting (Li and Shi 2011). Leng et al. (2009) showed that for larger TBM driving rates, the disturbed zone of the surrounding rock of the excavation is smaller and more stable. Chen et al. (2010) showed different degrees of damage of the surrounding rock within a range of $10 \mathrm{~m}$. During the TBM works the main damage or cracking developed in a range within $7 \mathrm{~m}$ from the free face, while the most severe damage occurred within a range of $3 \mathrm{~m}$. The range of damage of the rock in the direction of the tunnel axis is about $9 \mathrm{~m}$. Gong et al. (2010) showed that under high geostress, TBM does not operate in an optimal state above a specific value of the thrust force. Innaurato et al. (2007) showed a limited influence of the confining stress versus the thrust increment required for breaking the rock. Bilgin et al. (2006) indicated through experiments that the uni-axial compressive strength of the rock is best correlated with the measured cutter performance values. Fukui and Okubo (1999) found, by experiments, a method for estimating rock strength using TBM cutting. Yagiz (2006) established an empirical equation for the prediction of TBM performance using the actual TBM field data and intact and mass rock properties. Innaurato et al. (2003) evaluated a model that predicts the distributed displacement and stresses under TBM cutting. Bilgin et al. (2012) indicated that the chisel tools were superior to the disk cutters in especially soft to medium strength rocks. Balci (2009) showed that fracture characteristics of the rock formation affect to some extend greatly the TBM performance. Dollinger et al. (1998) concluded based on experiments that the TBM punch test has proven itself to be a powerful laboratory tool for evaluating rock drilling capacity. Gertsch et al. (2007), based on experiments, showed why the cutter spacing near $76 \mathrm{~mm}$ is commonly found on tunnel boring machines operating in hard rock. Gong et al. (2007) showed that a critical point exists in the TBM penetration curves. Saffet (2008) concluded that TBM performance could be estimated as a function of rock properties utilizing a new equation. Acaroglu et al. (2008) built a model based on experience, which predicts specific energy requirements of TBM disk cutters. Ebrahim and Jamal (2008) showed that the amount of the tunnel convergence has a direct relationship with the percentage of rock fragments. Khademi et al. (2010) introduced a convenient empirical predictive model for TBM performance by using a rock mass rating (RMR) system. Sun et al. (2011) showed that the shape and areas of relaxation zone of the tunnel and also the stress and deformation of the tunnel lining are significantly influenced by joint set and in situ stress parameters. Saffet and Halil (2011) built a model predicting the performance of TBM using particle swarm optimization 
techniques (PSO). Hassanpour et al. (2011) showed that there are strong relationships between geological parameters like joint spacing and RQD, but especially the field penetration index (FPI) and TBM performance parameters.

The above research is mainly concentrated on the macroscopic characteristics of the surrounding rock, while a small proportion of the research is focused on the micromechanisms. In this paper, the mechanical effects are presented of the drilling of the deepest tunnels in the world namely the Jinping diversion tunnels. The tunnels were excavated, respectively, by TBM and drill-blasting. The analyses of the mechanical response of the surrounding rocks were done through electron microscopic scan tests, acoustic emission tests and relaxation depth tests. It is expected that the research provides some basic data for tunnel failure mechanism and reinforcement measures of similar projects.

\section{Materials and methods}

A large-scale hydropower project "Jinping II Hydropower Station" is carried out in the Yalong River Basin in West China, which makes use of a water diverting method to generate electric power. The average length of the four water diverting tunnels is $16.25 \mathrm{~km}$, and the largest burial depth is about $2,525 \mathrm{~m}$. The largest geo-stress is about $70 \mathrm{MPa}$, and the water stress is as high as $10.2 \mathrm{MPa}$. The values of this hydropower station are rarely seen in the world.

The $1 \#$ and the $3 \#$ water diverting tunnels are excavated by the TBM method, and the 2\# and the $4 \#$ water diverting tunnels are excavated by the drill-blasting method. The four tunnels are parallel to each other, and the distance from each other is only $50 \mathrm{~m}$, these unique geological conditions provide a reliable basis of contrast for this research.

Macroscopic failure of the surrounding rock is the results of micro-cracks develop to a certain degree under high geo-stress. It is necessary to capture the fracture process of the rocks and analyze the characteristics during loading to master the mechanism and the features of tunnel deformation and failure under different excavation conditions.

\subsection{Electron microscopic scan test}

The S-3,000 N type scanning electronic microscope produced by Hitachi, Ltd and the EX0-350X gamma ray spectrometer produced by the HORIBA were used for electron microscopic microstructure analysis of samples from the surrounding rock excavated by the TBM and drill-blasting methods.

The test samples are classified as drill-blasting fracture samples and TBM fracture samples. There are 16 groups of samples. Samples, whose fracture plane are relatively obvious, were selected to be sliced, to a size of $1 \mathrm{~cm}$ (length) $\times 1 \mathrm{~cm}$ (width) $\times 0.5 \mathrm{~cm}$ (thickness). When the sample is in cutting, to protect the sample from being damaged, a thin layer of cotton is placed on the scanning fracture plane; next, cotton gauze is used to wrap the fracture plane, and then, the rest fracture plane is cut.

According to the standard fracture morphology, typical rock fractures can be classified into crack fractures, shear fractures and crack-shear compound fractures. The crack fracture morphology includes an "along the crystal crack surface," a "transgranular crack surface" and a "stepped crack surface." The shear fracture morphology includes a "scratching along the crystal surface," a "transgranular shear surface," a "stepped friction surface" and a "flat 
shear surface." The crack-shear compound fracture morphology shows characteristics between the crack fracture and the shear fracture.

\subsection{Acoustic emission test}

Acoustic emission (Fig. 1) happens on rocks and other brittle materials due to factors such as load fluctuation, temperature variation. Acoustic emission is a natural phenomenon when rocks and brittle materials rapidly release part of the deformation energies, which happens along with the deformation process.

The mode of rock macroscopic failure under uni-axial compression condition mainly includes brittle tensile failure, single bevel shear failure and $\mathrm{X}$-shape conjugate shear failure. The modes of rock microscopic fracture include crack propagation (Fig. 2a), crystal slip (Fig. 2b) and laceration (Fig. 2c). Therefore, the acoustic emission signal is directly related to rock deformation, the internal micro-crack extension and the rock loading speed.

Leng et al. (2009) has analyzed the relationship between rock acoustic frequency and rock deformation, according to the acoustic emission peak frequency, the $\operatorname{ratio}\left(\sigma_{\mathrm{e}} / R\right)$ between the initial stress value $\sigma_{\mathrm{e}}$ and compressive strength $(R)$, the accumulated frequency number. The rock acoustic emission characteristics are divided into four types: type I: mass incremental type, type II: concentrated emission type, type III: sudden emission type which mainly happened in the intact and high-strength rock. Type IV is called sporadic emission, which mainly happened in uneven rock structures.

The acoustic emission test analysis was used to discover the internal microscopic failure process, and the microscopic failure mechanism of the surrounding rock samples excavated by the drill-blasting and TBM method. The test samples are, respectively, collected from the 4\# drill-blasting tunnel (pile number K10 + 368) and the 1\# TBM tunnel (pile number $\mathrm{K} 10+293$ ). The rock samples consist of white fine-grained marble which are cut into columns with a size of $7.5 \mathrm{~cm} \times 2.5 \mathrm{~cm} \times 2.5 \mathrm{~cm}$.

The test device comprises a rock mechanic integrated test system, including a MTS815 rock rigidness test machine imported from America and an AE-21C type rock acoustic emission detecting system, developed by the Shenyang Computer Institute.

The tests include a method of continuous loading with the following speeds, (1) $0.3125 \mathrm{kN} / \mathrm{s}$, (2) $0.625 \mathrm{kN} / \mathrm{s}$, (3) $1.25 \mathrm{kN} / \mathrm{s}$, (4) $2.5 \mathrm{kN} / \mathrm{s}$, (5) $5 \mathrm{kN} / \mathrm{s}$.

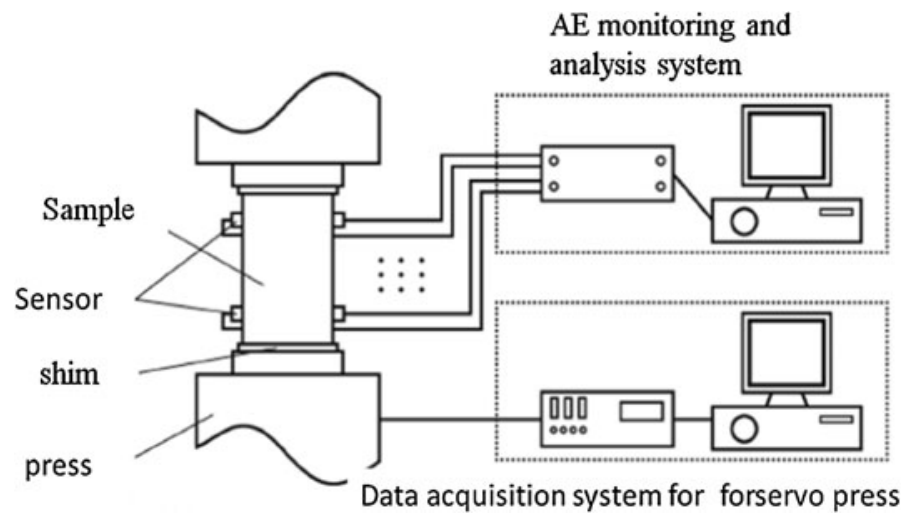

Fig. 1 Schematic diagram of the experimental AE set up 

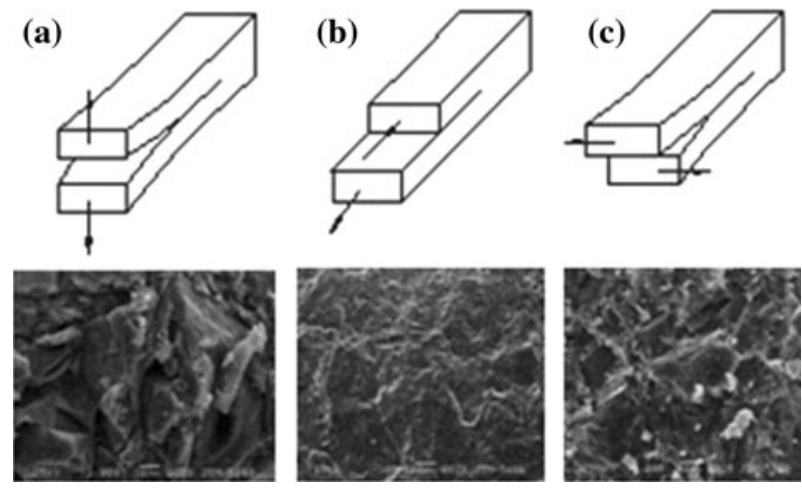

Fig. 2 Rock microscopic failure modes. a Crack propagation, b crystal slip, $\mathbf{c}$ tear (laceration)

\subsection{Sound wave test of the surrounding rock stress relaxation belt}

The accurate measurement of the relaxation belt of the surrounding rock can help to analyze the influence of tunnel excavation and to design a safe but also economic beneficial length of the rock bolts. The relaxation belt of the tunnel is always tested by a penetrating sound wave method along parallel cross-holes.

\section{Results and analysis}

\subsection{Electron microscopic scan results and analysis}

Under the cutting, punching and shearing forces of the TBM excavator, the fracture morphology of rocks is mainly of the type:"Scratching along the crystal surface" and "transgranular shear surface" (Fig. 3). Figure 3a shows a fishbone-shaped pattern. The main cleavage cracks of the rock extend forward along the twin crystal plane and the basal plane, forming the laterals of the fish shape, and the intersected part of the two planes forms the fishbone in the middle. Figure $3 b$ shows a stripe pattern. The crystal slides and flows and a series of linear parallel stripes can be seen on the fracture. Figure $3 \mathrm{c}$ shows a "snake" slide pattern. When the crystals slide along a number of mutually intersected planes, linear bending strips appear like snake shapes. Figure $3 \mathrm{~d}$ shows a double sliding pattern because the crystals slide along two directions with long lines in one direction and short lines in the other direction.

Crack fracture of rocks mainly includes joint fracture and complete crystalline fracture. In general, the fracture morphology of TBM rock is mainly shearing fracture, while crack fracture is relatively seldom.

In case of drill- blasting, the fracture morphology of rocks is mainly crack fracture, and the shearing fracture is relatively small. The crack fracture is mainly complete crystalline fracture (Fig. 4). Figure 4a, c show intergranular fracture patterns. The crystals in Fig. 4c have large defects; most of the edges and corners are in grain shape, and therefore, the crystal boundary cementation is weak; Fig. 4b shows a transgranular crack surface and Fig. $4 \mathrm{~d}$ shows a strip pattern, with the cutting of a part of the crystals and sharp edges and corners. 

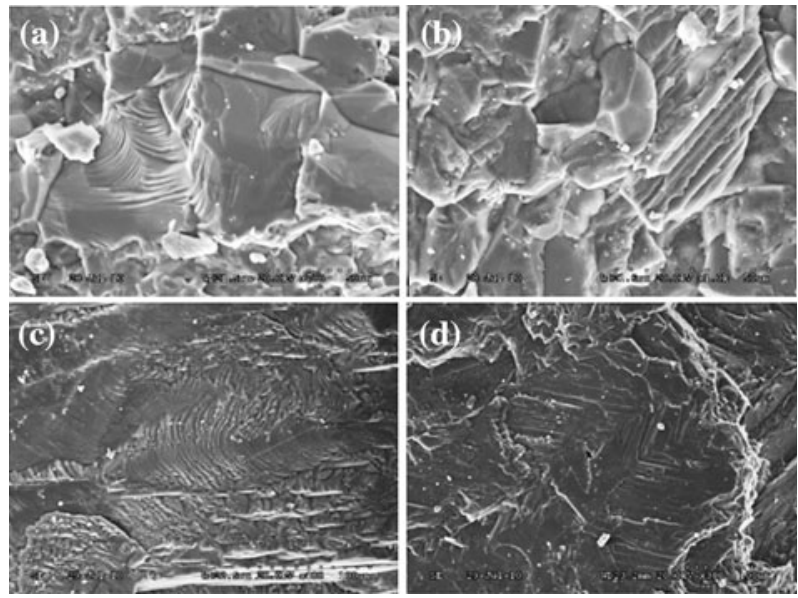

Fig. 3 The fracture morphology formed by the TBM method. a Fishbone-shaped pattern, b fracture stripe patter among crystals, $\mathbf{c}$ snake slide pattern, $\mathbf{d}$ double sliding pattern
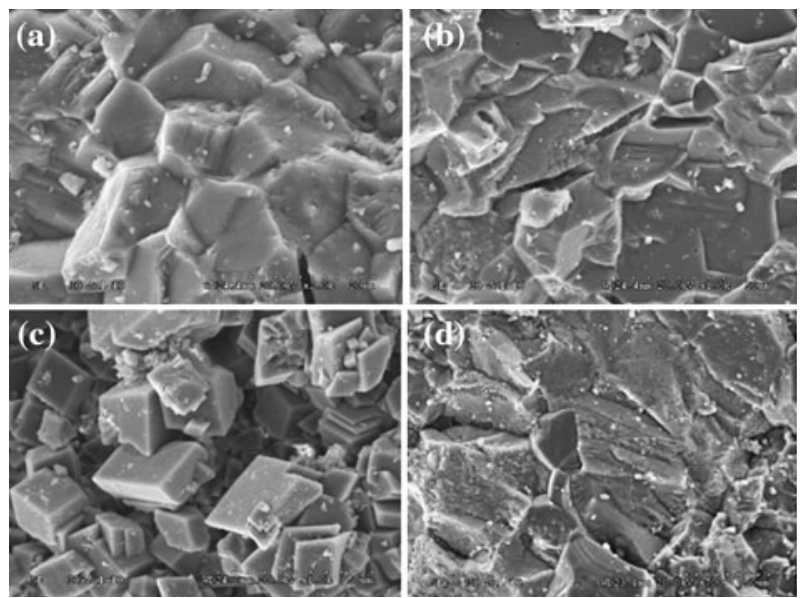

Fig. 4 The fracture morphology formed by the drill-blasting method. a Crack surface along the crystal, b transgranular crack surface, $\mathbf{c}$ transgranular crack surface, $\mathbf{d}$ strip pattern

\subsection{Result and analysis of acoustic emission}

According to the test results, the acoustic emission characteristics of marble belongs to type III.(see Sect. 2.2). Figures 5 and 6 show the rock deformation failure process and the concomitant rock acoustic emission properties under the two excavation techniques.

1. the whole stress-strain curves are basically similar to each other under low loading rates, The curve o-a belongs to the compaction stage; curve $\mathrm{a}-\mathrm{b}$ belongs to the elastic deformation stage, with a few acoustic emission phenomena; curve b-c belongs to the plastic deformation stage and still has a few acoustic emissions appearing; the curve after point $\mathrm{c}$ belongs to the failure stage where the marbles are damaged and accompanied by a large number of acoustic emission signals. The ringing counts up to 
Fig. 5 Stress-strain-ringing counts under drill-blasting condition

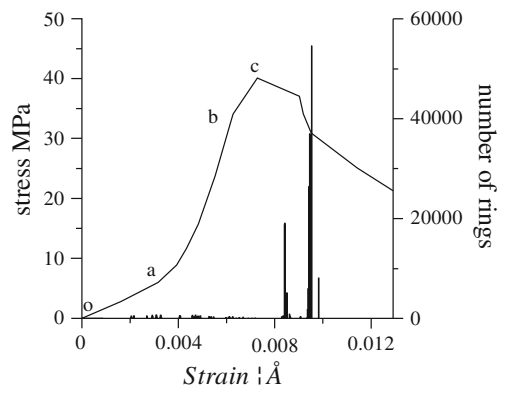

Fig. 6 Stress-strain-ringing counts under TBM condition

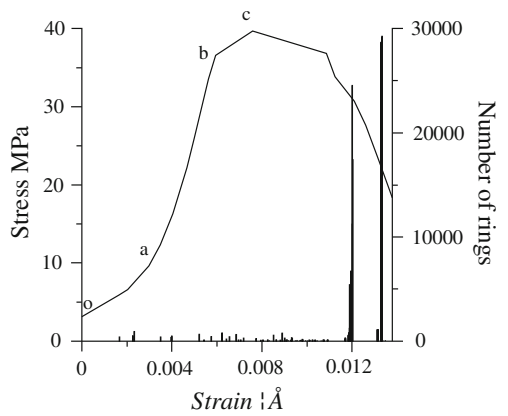

60,000 under the conditions of the drill-blasting method and up to 30,000 under the TBM method.

2. The ringing counts have the tendency of a slow-increase and steep-decrease. The period with frequent- and high-ringing counts occurs at larger strains for the TBM method than for the drill-blasting method.

3. The acoustic emission period of ringing counts is rather concentrated and belongs to the mass-concentration transition type. The ringing starts at the compaction phase and continues in the elastic and plastic phase, while clear peak values appear when the rocks are completely destroyed.

A comparison is made between the acoustic emission figures for different loading speeds according to the two methods. The stress-strain-ringing counts for five different loading speeds using the drill-blasting method are shown in Fig. 7.

The stress-strain-ringing counts under the TBM condition are shown in Fig. 8. Through comparative analysis, it was found that the stress-strain-ringing counts under TBM and drill-blasting method share a lot of similarities.

1. With an increase in the loading speed, the compaction stage becomes comparatively short, and in a later stage, a remarkable elastic deformation appears;

2. With an increase in the loading speed, the ultimate compressive strength of the marble has the tendency of dropping at first and rising later;

3. The stress-strain curves have the overall tendency of shifting to the left, and the main reason is the influence of the increasing loading rate. Only a small amount of deformation can lead to rock breaking. The stress-strain curve of low loading speed in the damaged stage is not sharp but flat, which shows strong anti-deformation capability after the damage; 

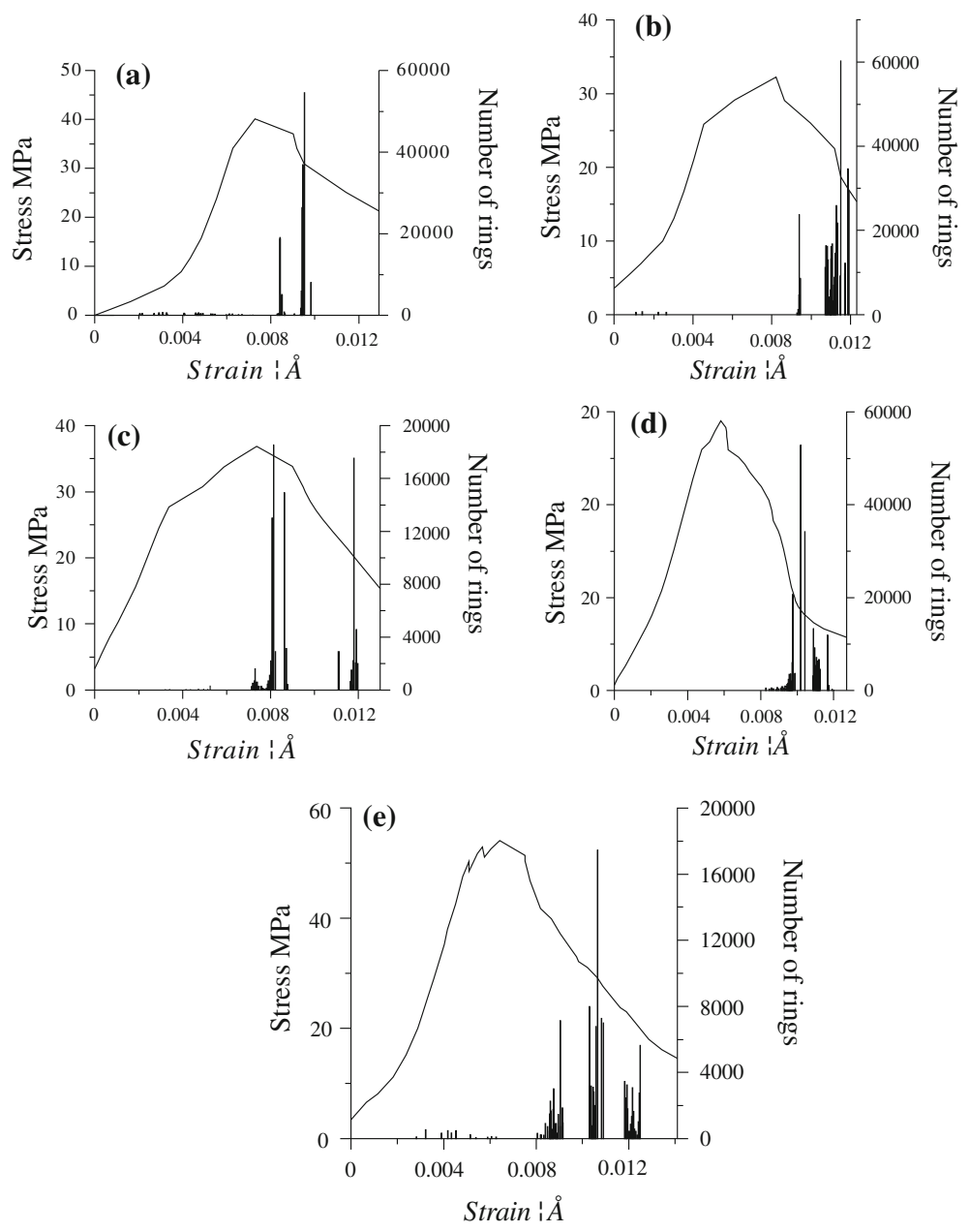

Fig. 7 Stress-strain versus ringing counts for different loading rates with the drill-blasting method. a loading rate $0.3125 \mathrm{kN} / \mathrm{s}$, b loading rate $0.625 \mathrm{kN} / \mathrm{s}$, c loading rate $1.25 \mathrm{kN} / \mathrm{s}$, d loading rate $2.5 \mathrm{kN} / \mathrm{s}$, e loading rate $5 \mathrm{kN} / \mathrm{s}$

4. The acoustic emission is mainly concentrated between strains from 0.008 to 0.014 . In this range, the marbles are obviously damaged.

Comparing the stress-strain curves for drill-blasting and the TBM method, we can find for all the curves two differences:

1. As a result of the explosive blasting impact, the stress-strain curve of the surrounding rock sample excavated by drill-blasting has a sharp peak, while the peak of the rock samples of the TBM tunnel is more flattened. The reason is that these rocks are not impacted by the explosions, which means that the rocks have a strong anti-deformation capability around the peak value.

2. At the same loading speed, the acoustic emission are concentrated in the strain domain between 0.008 and $\sim 0.012$ for the drill-blasting samples, while for TBM samples the 

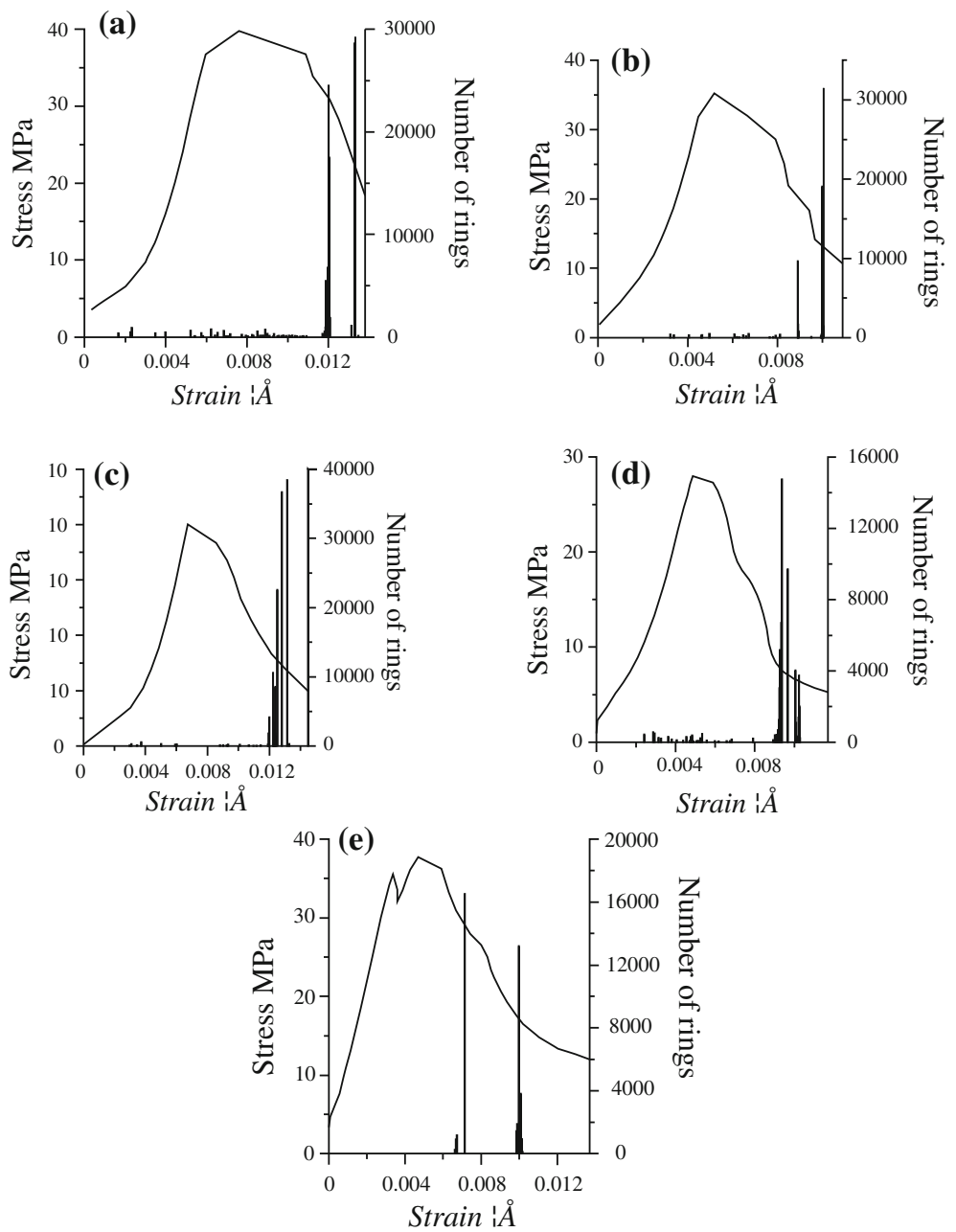

Fig. 8 Stress-strain versus ringing counts for different loading rates with the TBM method. a Loading rate $0.3125 \mathrm{kN} / \mathrm{s}$, b loading rate $0.625 \mathrm{kN} / \mathrm{s}$, $\mathbf{c}$ loading rate $1.25 \mathrm{kN} / \mathrm{s} \mathrm{d}$ loading rate $2.5 \mathrm{kN} / \mathrm{s}$, e loading rate $5 \mathrm{kN} / \mathrm{s}$

signals are concentrated in the strain domain between 0.010 and 0.014 . The macroscopic failure points of the samples are different, and the anti-deformation capability of the surrounding rocks in the tunnel excavated by the TBM method is stronger.

\subsection{Result and analysis of the sound wave detection and stress relaxation belt}

Under the same geological condition, the relaxation belt of the surrounding rock for the two excavation methods is shown in Figs. 9 and 10.

Figures 9 and 10 clearly show that the relaxation depth of the tunnel excavated by the drill-blasting method is $40-100 \mathrm{~cm}$ larger than the relaxation depth of the tunnel excavated 


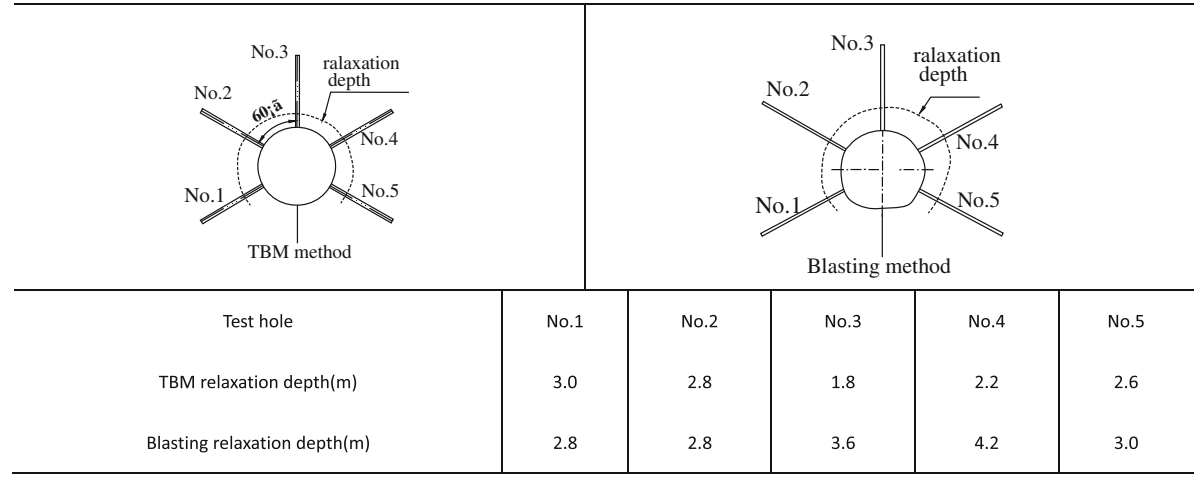

Fig. 9 K15 +700 sound wave detection result to measure the relaxation dept

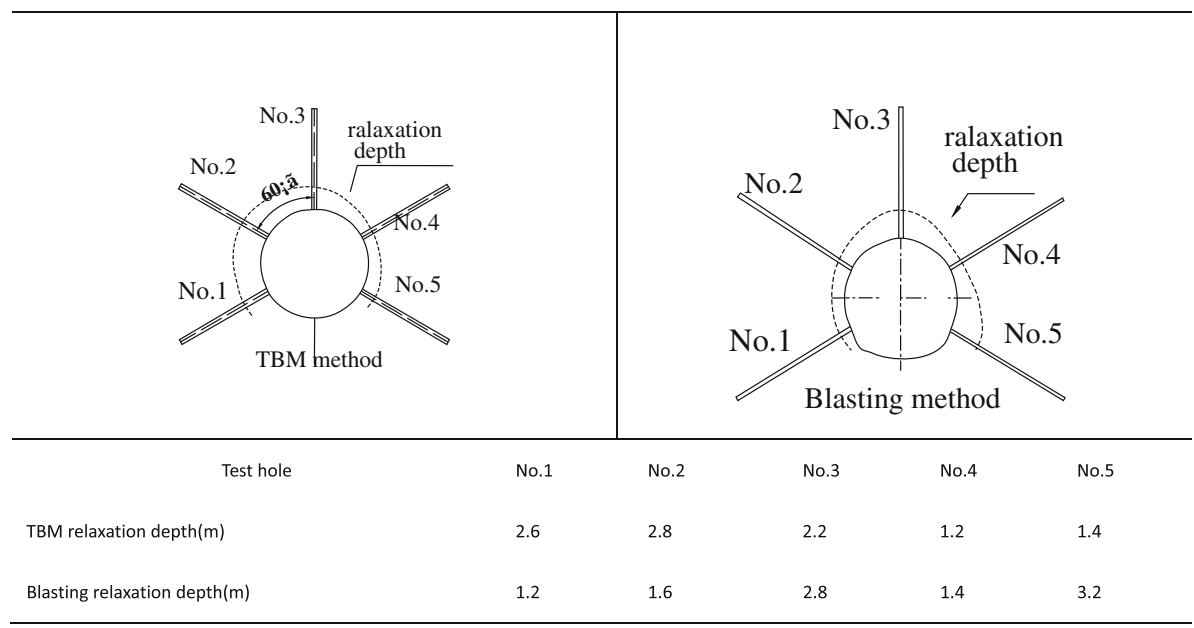

Fig. $10 \mathrm{~K} 15+150$ sound wave detection result to measure the relaxation depth

by the TBM. The blasting perturbation on the surrounding rock with the drill-blasting method is stronger, and therefore, the degree of damage of the surrounding rock is stronger than the degree of damage in the tunnel excavated by the TBM method. The reinforcement measures with the TBM method are timely taken, which limits the relaxation belt to extend deeper. This is good for the overall stability of the surrounding rock. However, the reinforcement measures during the drill-blasting method lags a certain distance behind the location of the excavation., which easily causes further damage to the surrounding rock. Therefore, in order to limit the relaxation ring variation, reinforcement measures should be improved in tunnels excavated in marbles by the drill-blasting method.

\section{Conclusion}

This paper uses electron microscopic scan tests, acoustic emission tests and relaxation depth tests to analyze the mechanical response of surrounding rocks which were excavated, 
respectively, by the TBM and drill-blasting method. The following conclusions can be drawn

1. According to the fracture morphology, it is obvious that different tunnel construction methods lead to the differences in the surround-rock fracture morphology. The TBM rock samples show mainly a shearing fracture morphology, and the drill-blasting samples show mainly a crack fracture morphology.

2. As a result of the impact wave by explosive blasting, the stress-strain curve of the surrounding rock sample excavated by the drill-blasting method has a sharp peak, while the rock samples in the TBM tunnel have a flattened peak. This means that the rock samples of the TBM tunnel have a strong anti-deformation capability around the peak value.

3. For the same loading speed, the ringing counts of rocks excavated by the drill-blasting method are concentrated within strains between 0.008 and 0.012 , while the ringing counts of rocks excavated by the TBM method are concentrated in the strain domain between 0.010-0.014. The macroscopic failure points of the samples are different, and the anti-deformation capability of the surrounding rocks in the tunnel excavated by the TBM method is stronger.

4. The relaxation depths of the tunnel excavated by the drill-blasting method are larger than the relaxation depth of the tunnel excavated by the TBM method (between $40 \mathrm{~cm}-100 \mathrm{~cm}$ ) under the same geological conditions. Reinforcement measures should be improved for tunnels excavated by the drill-blasting method.

Acknowledgments This project is supported by Independent Exploration Fund of State Key Laboratory of Geohazard Prevention and Geoenvironment Protection (SKLGP2011Z009) and Youth Training Fund (SKLGP2011Z012). Thanks for the help.

Open Access This article is distributed under the terms of the Creative Commons Attribution License which permits any use, distribution, and reproduction in any medium, provided the original author(s) and the source are credited.

\section{References}

Acaroglu O, Ozdemir L, Asbury B (2008) A fuzzy logic model to predict specific energy requirement for TBM performance prediction. Tunn Undergr Space Technol 23(5):600-608

Balci C (2009) Correlation of rock cutting tests with field performance of a TBM in a highly fractured rock formation: a case study in Kozyatagi-Kadikoy metro tunnel, Turkey. Tunn Undergr Space Technol 24(4):423-435

Bilgin N, Copur H et al (2006) Dominant rock properties affecting the performance of conical picks and the comparison of some experimental and theoretical results. Int J Rock Mech Min Sci 43(1):139-156

Bilgin N, Copur H, Baldi C (2012) Effect of replacing disc cutters with chisel tools on performance of a TBM in difficult ground conditions. Tunn Undergr Space Technol 27(1):41-51

Chen B-R, Feng X-T, Xiao Y-X et al (2010) Acoustic emission test on damage evolution of surrounding rock in deep-buried tunnel during TBM excavation. Chin J Rock Mech Eng 29(8):1562-1569

Dollinger GL, Handewith HJ, Breeds CD (1998) Use of the Punch test for estimating TBM performance. Tunn Undergr Space Technol 13(4):403-408

Ebrahim F, Jamal R (2008) Correlation of tunnel convergence with TBM operational parameters and chip size in the Ghomroud tunnel, Iran. Tunn Undergr Space Technol 23(6):700-710

Fukui K, Okubo S (1999) Rock-properties estimation by TBM cutting force. In: 9th international congress on rock mechanics. Paris, France, pp 1-2

Gertsch R, Gertsch L, Rostami J (2007) Disc cutting tests in Colorado red granite: implications for TBM performance prediction. Int J Rock Mech Min Sci 44(2):238-246

Gong Q-M, Zhao J, Jiang Y-S (2007) In situ TBM penetration tests and rock mass boreability analysis in hard rock tunnels. Tunn Undergr Space Technol 22(3):303-316 
Gong Q-M, She Q-R, Hou Z-S et al (2010) Experimental study of TBM penetration in marble rock mass under high geostress. Chin J Rock Mech Eng 29(12):2522-2532

Hassanpour J, Rostami J, Zhao J (2011) A new hard rock TBM performance prediction model for project planning. Tunn Undergr Space Technol 26(5):595-603

Innaurato N, Oggeri C, Oreste PP et al (2003) Problems concerning cutting tool performance during TBM work: modelisation and testing of the rock under the action of the tool. In: 29th ITA world tunnelling congress.Amsterdam, The Netherlands, pp 477-482

Innaurato N, Oggeri C, Oreste PP et al (2007) Experimental and numerical studies on rock breaking with TBM tools under high stress confinement. Rock Mech Rock Eng 40(5):429-451

Khademi HJ, Kourosh S, Bahram R et al (2010) Performance prediction of hard rock TBM using rock mass rating (RMR) system. Tunn Undergr Space Technol 25(4):333-345

Leng X-L, Sheng Q, Zhu Z-Q et al (2009) Study on excavation disturbed zone in surrounding rock of tunnel with various TBM driving rates. Chin J Rock Mech Eng 28(2):3692-3698

Li H-Y, Shi G-Y (2011) The numerical simulations of forces acting on TBM disc cutters with the consideration of confining pressure and damage in rocks. In: International conference on vibration. Shanghai, People's Republic of China, pp 105-107

Ribacchi R, Fazio AL (2005) Influence of rock mass parameters on the performance of a TBM in a gneissic formation (varzo tunnel). Rock Mech Rock Eng 38(2):105-127

Saffet Y (2008) Utilizing rock mass properties for predicting TBM performance in hard rock condition. Tunn Undergr Space Technol 23(3):326-339

Saffet Y, Halil K (2011) Prediction of hard rock TBM penetration rate using particle swarm optimization [J]. Int J Rock Mech Min Sci 48(3):427-433

Sun J-S, Guo H-J, Lu W-B et al (2011) Analysis of TBM tunnel behavior in jointed rock mass. In: International conference on civil engineering and transportation (ICCET 2011). Jinan, People's Republic of China, pp 2033-2036

Yagiz S (2006) TBM performance prediction based on rock properties. In: International symposium of the international-soci.Liege, Belgium, pp 663-670 